\title{
Matrix e Zardoz: confluências de um universo cibercultural ${ }^{1}$
}

\author{
Geraldo de Lima²
}

Resumo: Este artigo tem como objetivo fazer uma analise comparativa entre a trilogia do filme Matrix e outros filmes que abordaram a questão de mundos paralelos virtuais e do uso da tecnologia dentro do universo da cibercultura. A existência de elementos mitológicos, religiosos de mesma base imagética em Matrix, podem ser verificados em filmes da década de 70, como Zardoz (1974) e Westword (1973), da década de 80, como Tron (1982) e Videodrome (1983), e nos anos 90, como Cidade das Sombras (1998). Todos eles questionam a imersão no mundo virtual e na tecnologia como motivadora de modificações nos padrões de existência humana e da relação próxima entre os homens e as máquinas.

Palavras-chave: Matrix, cinema, cibercultura, Zardoz.

\begin{abstract}
This article is a comparative analysis between the Matrix movie trilogy and other films that addressed the issue of parallel virtual worlds and the use of technology within the universe of cyberspace. The existence of mythological elements - the same base of religious imagery in The Matrix - can be seen in movies of the 70's, as Zardoz (in 1974) and Westword (1973), the 80's, as Tron (1982) and Videodrome (1984), and in the 90's, as Dark City (1998). All of these movies question the immersion in the virtual world and technology as a motive to change the patterns of human existence and the close relationship between men and machines.
\end{abstract}

Keywords: Matrix, cinema, cyberculture, Zardoz. 


\section{Matrix e algumas influências}

A obra de Matrix ${ }^{3}$ é um agrupamento de diversos fragmentos simbólicos, ideológicos, religiosos e mitológicos. Além dessa mistura que remete ao pósmodernismo, há uma profunda influência de filmes produzidos décadas antes dele e que já traziam em seus enredos, enquadramentos e fotografias uma carga de elementos que viriam a ser tratados dentro do movimento da cibercultura.

A questão que este artigo propõe a tratar não é meramente uma comparação de enredo ou enquadramentos parecidos entre Matrix e outros filmes como referência, mas mostrar que Matrix trouxe elementos desses filmes que valem a pena ser discutidos sob a ótica do movimento da cibercultura. $\mathrm{O}$ trabalho procura analisar se houve uma evolução no pensamento cibernético, que em dado momento foi refletido na complexa estrutura fílmica de Matrix.

Os principais filmes analisados, comparando-os com Matrix, são: Zardoz (1974), Cidade das Sombras (1998) e Westworld (1973). Além desses, outros também são referenciados em menor intensidade, como Tron (1982), Johnny Mnemonic (1995), Fantasma do Futuro (1995) e Videodrome (1983).

\section{Zardoz e Matrix}

Em Zardoz (1974), filme dirigido por John Boorman, verificamos que existem grandes semelhanças com Matrix, tanto no enredo como em diversas imagens do espaço no qual os filmes se passam. Zardoz é o nome de um deus que obriga os homens a trabalhos forçados, oprimidos por um exército de homens armados seguidores desse deus opressor. De tempos em tempos o deus Zardoz, na forma de uma cabeça de pedra voadora, vem para entregar armas ao seu exército de assassinos obedientes e levar a produção de trigo embora.

Em uma dessas visitas, um dos assassinos chamado Zed (Sean Connery) se esconde na cabeça de pedra e foge para o mundo do deus Zardoz. Nesse momento começam algumas semelhanças com Matrix. 
A cabeça do Deus pedra, que representa a sustentação de toda tecnologia conhecida, é semelhante à cabeça do Deus máquina que aparece no final do terceiro filme da série, Matrix Revolution. Em Matrix o Deus máquina também é o senhor poderoso das máquinas e da alta tecnologia existente num futuro fictício.

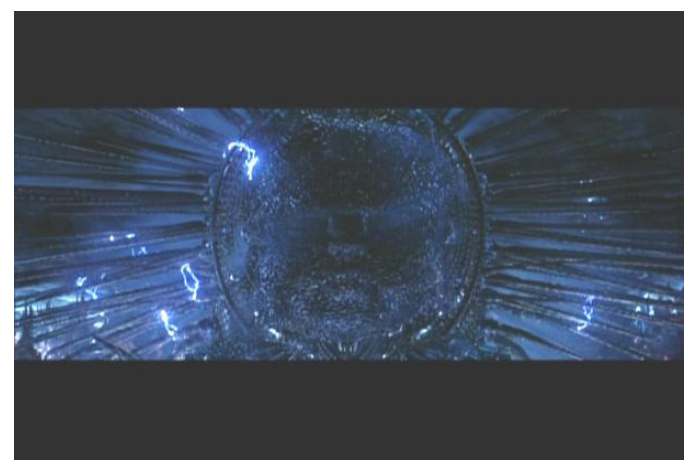

Fig. 1 - Matrix Revolutions

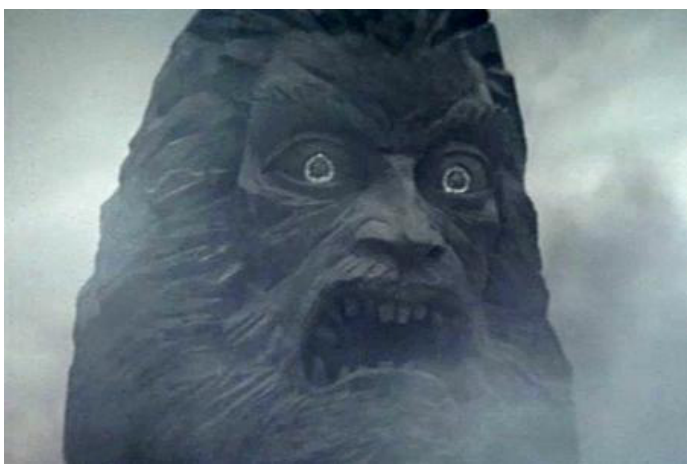

Fig. 2 - Zardoz

No momento em que Zed sai de dentro do trigo para saber onde está ele começa a emergir com a arma erguida acima do corpo e o trigo vai se esparramando a sua volta. No filme Matrix existe uma grande simbologia remetendo ao nascimento. O próprio nome do personagem principal, Neo, remete ao "novo", como o termo "Neonatal" é usado para o que é recém-nascido.

Nas figuras abaixo, três desses momentos de renascimento:

1) Na primeira imagem (Figura 03) uma cena de Videodrome, em que existe uma "doença" que contagia a todos que vêem uma fita do programa Videodrome. O vídeo domina as pessoas e as faz renascer para uma nova visão (ou ilusão) da técnica com o corpo, onde gritam "Viva a nova carne". Uma visão pessimista para o controle do homem pela imagem.

2) Na segunda imagem (Figura 04) uma cena de Zardoz, quando Zed sai de dentro do trigo com arma na mão. Esta cena é marcante no filme, pois a partir dali ele entra em contato com os "deuses" de Zardoz, que na verdade são cientistas evoluídos e imortais que criaram a divisão entre os povos e oprimem pelo poder tecnológico. 
3) Na terceira imagem (Figura 03), uma cena de Matrix, quando Neo sai do casulo após tomar a pílula vermelha, renascendo para um novo mundo, o mundo da máquina.

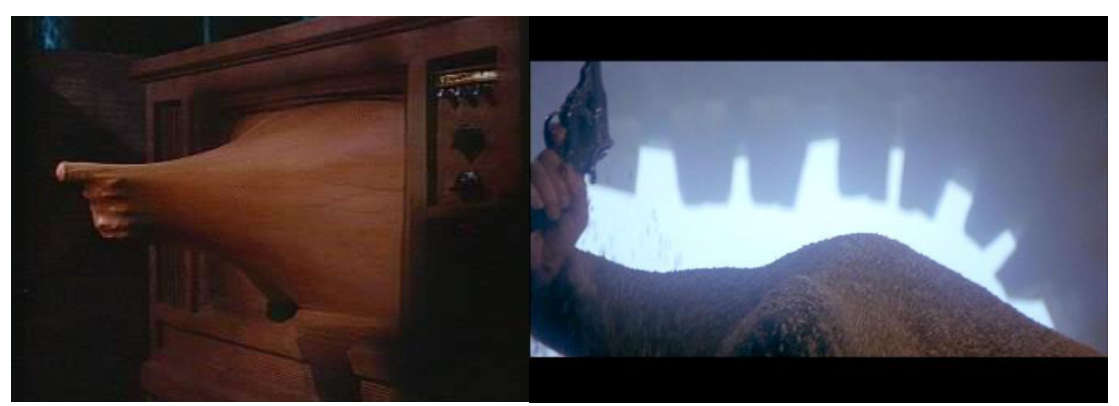

Fig. 3 - Cena de Videodrome arma saindo da TV

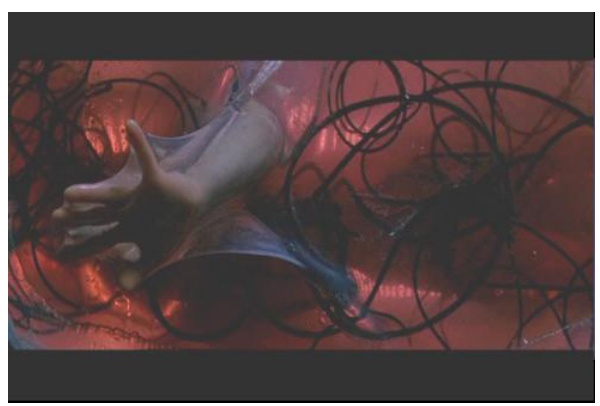

Fig. 5 - Cena de Matrix - Neo saindo do casulo

Nas três cenas, além das semelhanças das imagens, há um nascimento para um novo mundo, no qual a tecnologia é dominadora do homem. Os três protagonistas são "chamados" para enfrentar esta tecnologia "vilã" e são igualmente seduzidos por ela.

Na cena seguinte ao seu "nascimento" dentro da cabeça de pedra, em Zardoz, Zed olha para o lado onde existem casulos, semelhantes a bolhas plásticas, com pessoas nuas e paralisadas dentro (Figura 07). Depois descobrimos que essas pessoas estão ali para se regenerar de algum ferimento ou para rejuvenescer. A cena remete perfeitamente a cena do despertar de Neo do casulo na cidade das máquinas (Figura 06). Até mesmo a posição do corpo de ambos e o tons de cor, meio azulados e avermelhados são parecidos. Outra semelhança é que Neo ainda está com seu conector plugado na nuca, e Zed estar com um "rabo de cavalo" em seu cabelo, duas extensões aparentes nas imagens. 


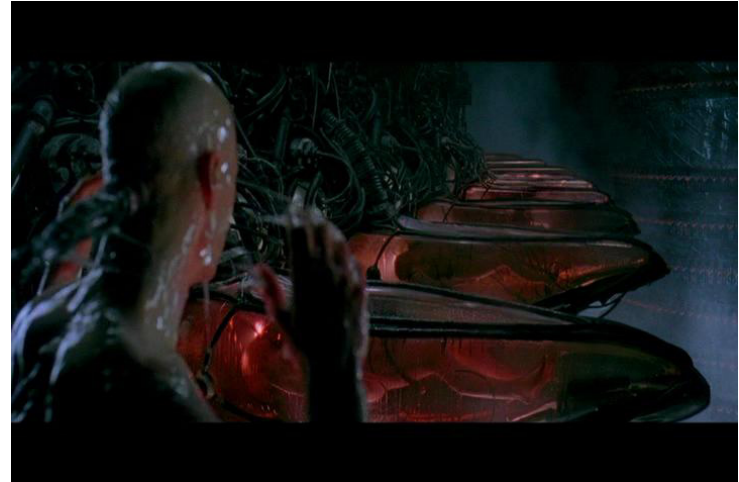

Fig. 6 - Cena de Matrix - Neo vê pessoas em casulos

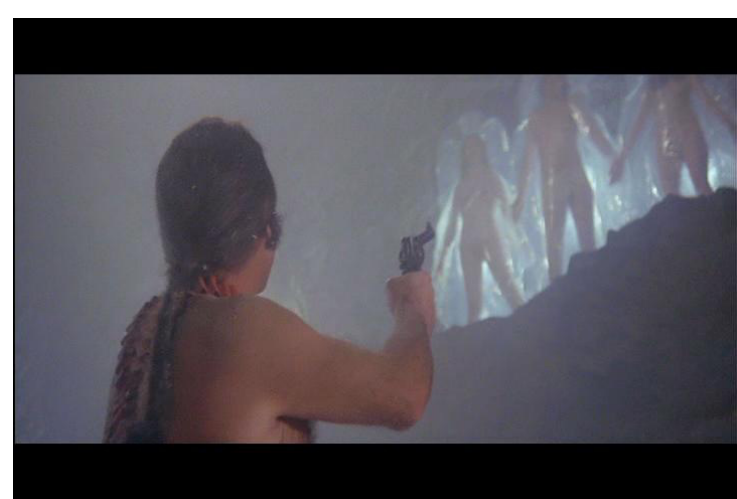

Fig. 7 - Cena de Zardoz - Zed vê pessoas em casulos

Zed e Neo têm semelhanças até no nome, com três letras apenas e na forma com que são tratados por outros habitantes do mundo que acordaram. São chamados de: "the one" termo em inglês que quer dizer "o escolhido".

Eles evoluem no mundo novo que encontraram desenvolvendo poderes capazes de controlar o espaço a sua volta. As cenas relativas às Figuras 08 e 10, abaixo, ocorrem no final dos filmes e mostram os dois protagonistas usando seus poderes. Observe o enquadramento com a câmera em posição perpendicular e plano médio e os olhos dos heróis da trama semicerrados, demonstrando uso de enorme força mental para controlar o mundo físico a sua volta. Existe nessas cenas uma provável ação de ativação do imaginário fílmico dos criadores da obra Matrix, que devem ter em seu repertório o filme Zardoz.

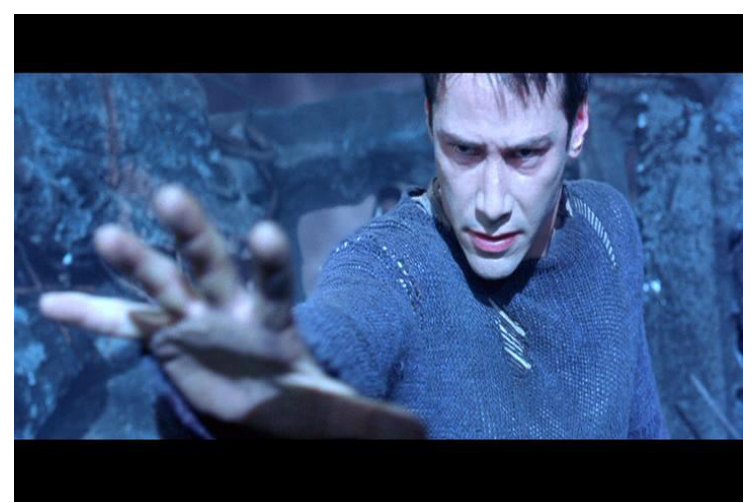

Fig. 8 - Cena de Matrix Reloaded

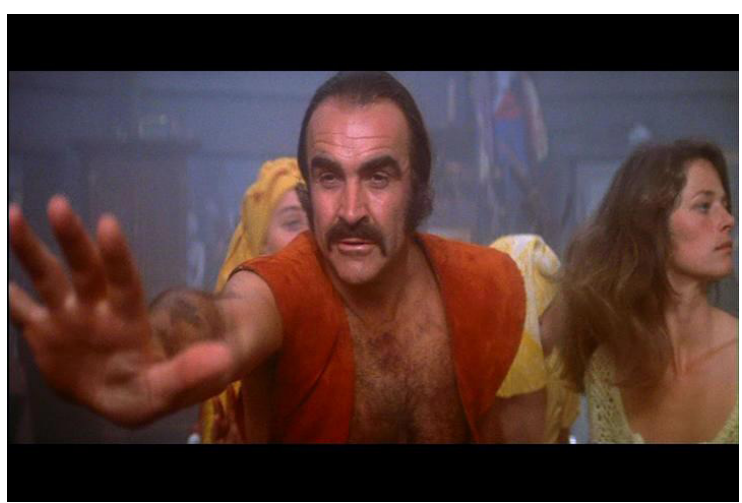

Fig. 10 - Cena de Zardoz 
Isto é apenas uma suposição baseada nas imagens e no enredo desses filmes, visto que não encontramos nenhuma referência direta citada pelos autores ou produtores de Matrix.

Há também uma demonstração da evolução do imaginário tecnológico espelhado nesses filmes. A tecnologia de Zardoz tem uma mistura de computadores de última geração e magia, comunica-se através de cristais e são uma IA (inteligência artificial) que não aparecem de forma física e humana. É uma voz que conversa com os cientistas e os ajuda a controlar o mundo chamado Vórtex.

Vortéx é a cidade onde os cientistas se isolaram para compor uma sociedade perfeita. É uma espécie de oásis, protegido por uma redoma invisível longe da miséria do resto da humanidade, e seria o equivalente ao mundo da máquina em Matrix. Os cientistas seriam o equivalente aos programas, e as IA's são, em Matrix, como o Oráculo, o Merovingio etc., programas inteligentes, que têm humor, prazeres e defeitos como os humanos, e aparecem também na forma humana.

Tanto os programas quanto os cientistas são imortais e vivem em um mundo de ilusão sustentados pelos humanos, que plantam trigo em Zardoz e geram energia em Matrix.

As cenas abaixo nos remetem a questão de como o homem vê a tecnologia em cada momento de sua história. Os dois protagonistas dentro da máquina e em multiplicidade demonstram o poder de se duplicar, que é a marca mais evidente das tecnologias da modernidade. Neo e Zed entram no núcleo do computador, a Fonte em Matrix e o Tabernáculo em Zardoz, e vêem a si mesmo refletidos, sendo Neo multiplicado nos monitores e Zed nos cristais (figuras 11 e 12). 


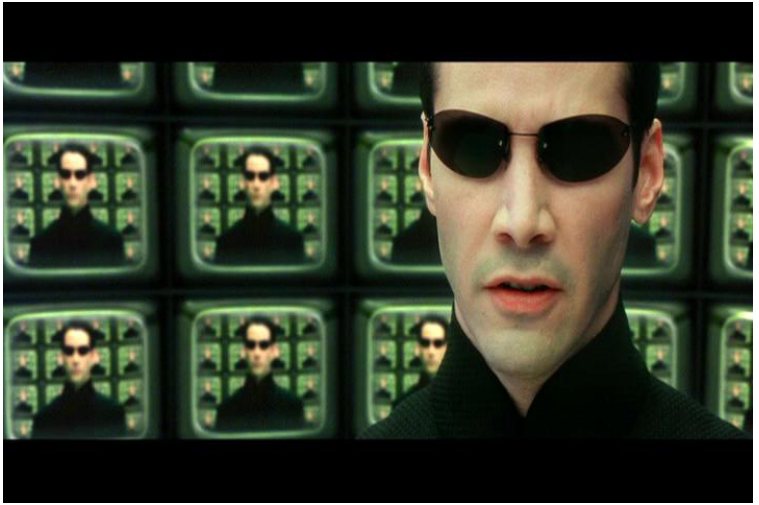

Fig. 11 - Cena de Matrix - Neo enfrenta o programa mestre, o arquiteto dentro da "Fonte"

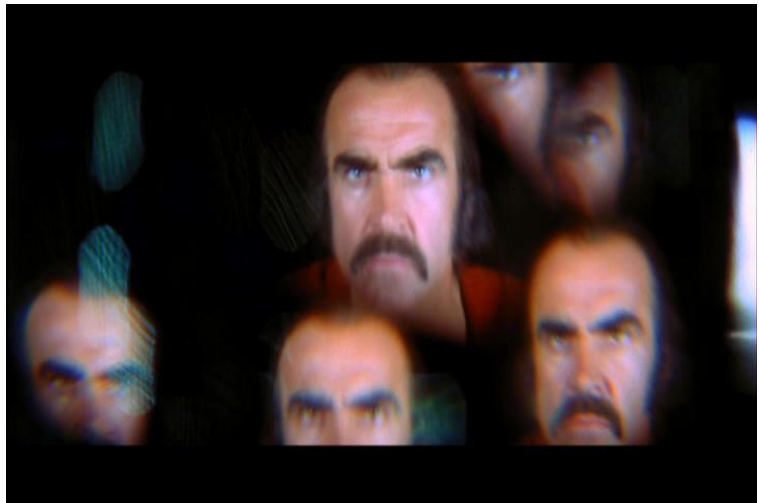

Fig. 12 - Cena de Zardoz - Zed dentro do computador do Vortéx

Cada filme foi criado dentro do contexto de sua época histórica. $\mathrm{Na}$ década de 70 de Zardoz a tecnologia digital ainda era pouco difundida; o homem começava sua hibridação com a máquina, mostrada no filme através do implante de cristais no cérebro dos imortais. Puros e brilhantes, os cristais eram o "link" com a máquina e representavam a soberania do saber perante aqueles que não tinham o conhecimento, os selvagens (figura 13).

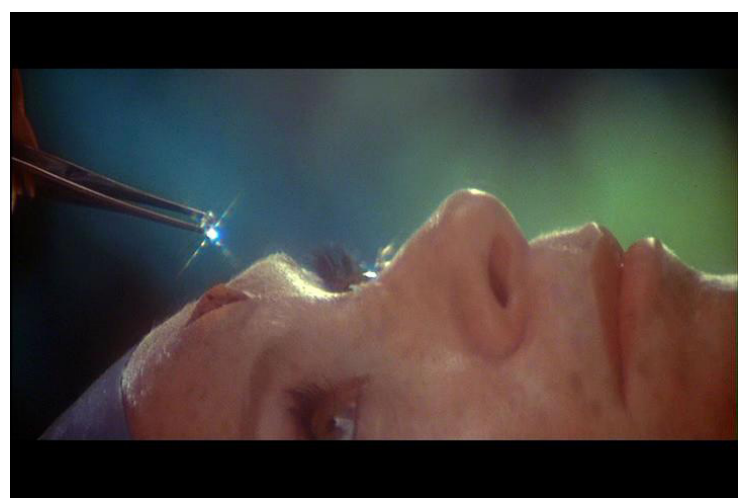

Fig. 13 - Cena de Zardoz

Zardoz termina com a morte dos sábios pelos selvagens que eles próprios doutrinaram, como uma demonstração de aversão ao que é tecnológico e sábio.

Matrix já partilha dos pensamentos tecnoculturais do final de década, do século e do milênio, uma verdadeira coletânea fílmica da sociedade pós- 
moderna aderente ao movimento da cibercultura. Diferente de Zed, Neo não é um selvagem, mas um habitante graduado nos conhecimentos da informática, um híbrido homem e máquina, um ser em busca da perfeição, pois o conhecimento é inserido diretamente em seu cérebro através de "downloads" do saber prático, não por cristais, mas por megabytes (ou algo similar em 2199) que trafegam em seu cérebro.

No final da trilogia, Neo acaba por defender as máquinas e a humanidade de outra criatura, um mutante que é "meio-Neo" e "meio-máquina", chamado Agente Smith, talvez outra etapa de uma evolução tecnológica. Neo se oferece em sacrifício, como um "messias-impuro" como diz o estudioso da cibercultura Erick Felinto:

Chamo a estes personagens [de Matrix] de "messias-impuros", pois suas trajetórias se desenvolvem no quadro de um simbolismo messiânico. Eles têm a função de "redimir", de "salvar", de "ensinar" uma humanidade decaída, estabelecendo uma ponte entre o humano e o além-do-humano (FELINTO, 2005, p. 50).

Neo e Zed são esses "messias-impuros" contaminados por artefatos técnicos e com uma missão "sagrada" de trazer a paz ao mundo onde existe uma guerra declarada entre a humanidade e suas próprias criações.

\section{Matrix e outros filmes}

Nessa análise, Zardoz foi o filme que mais trouxe referencias associadas à Matrix. Seu roteiro, suas imagens e símbolos são extremamente próximos e pertinentes. Depois dele, temos outros que também comungam cenas próximas, demonstrando que o imaginário com base nestes produtos fílmicos circulantes influenciou a obra de Matrix com bastante evidência.

Entre eles, destaca-se o filme Cidade das Sombras (1998), do diretor Alex Proyas. Começamos com as primeiras cenas de Cidade das Sombras (1998) e Matrix Reloaded (2003): há em ambos a imagem de um relógio apontando 
para a meia-noite. Em Matrix o relógio é construído pelo código da máquina, evidenciando que ele está dentro da simulação da máquina (figura 14). Em Cidade das Sombras, ele é destaque para mostrar que todos os dias, naquele horário, o espaço físico compreendido naquela cidade se transforma (figura 15).

Em Matrix o horário está marcando o momento em que Trinity (namorada de $\mathrm{Neo}$ ) invade um centro de produção de energia a fim de salvar Neo de um perigo eminente e ajudá-lo a descobrir os segredos da Matrix.

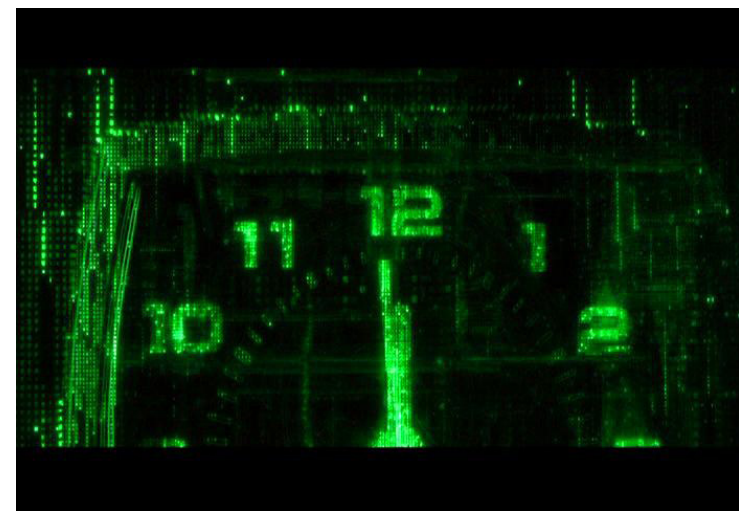

Fig. 14 - Cena de Matrix Reloaded

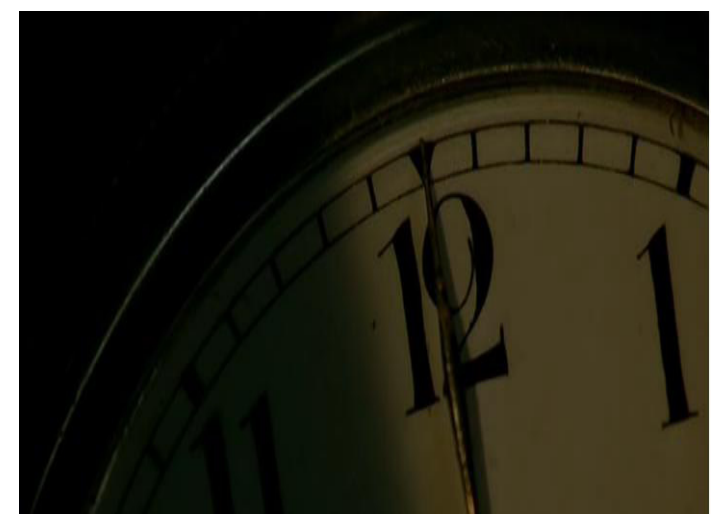

Fig. 15 - Cena de Cidade das Sombras

Meia-noite é um sinal de que um novo dia vai começar. Tanto em Matrix como em Cidade das Sombras, esse horário traz um significado maior que o próprio tempo a ele associado, e após esse tempo os espaços vão se transformar e as realidades daqueles mundos virtuais não serão mais as mesmas.

Em outra cena de Matrix Reloaded, o agente Smith se multiplica sem fim, para controlar a Matrix, o mundo dos homens e o da máquina (Figura 16). Todos se tornam iguais a ele e não existe um original (como já foi dito sobre Zardoz e a questão da multiplicidade de cópias das novas tecnologias). Em Cidade das Sombras, os alienígenas também são idênticos uns aos outros, tem memória coletiva e fazem experiências para entender como os humanos têm sua identidade única. Fazem testes onde a memória implantada é usada para saber se vivemos por causa delas, ou se somos mais do que as memórias e suas reações, quando são transformadas artificialmente (figura 17). 


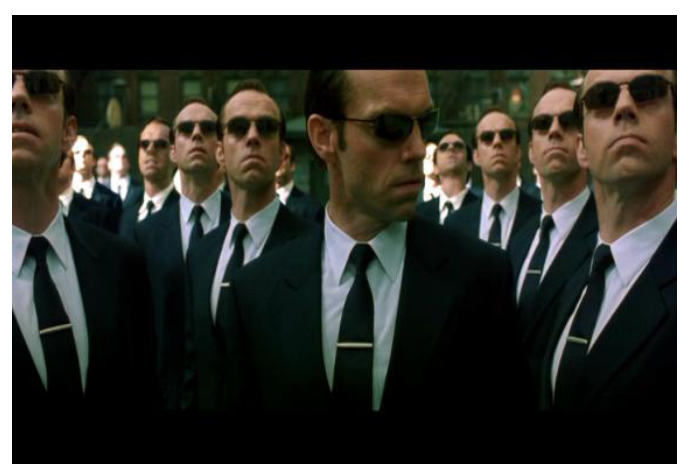

Fig. 16 - Cena de Matrix Reloaded

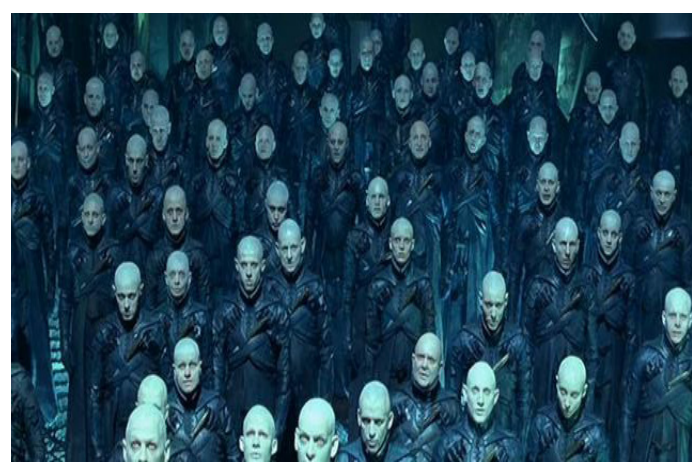

Fig. 17 - Cena de Cidade das Sombras

No final de Matrix Revolutions (2003) e Cidade das Sombras (1998), o mundo virtual de Matrix e o real em Cidade das Sombras, começam a se transformar, após a batalha final para que o bem triunfe. A reconstrução é semelhante nas cenas que se seguem abaixo (figuras 18 e 19).

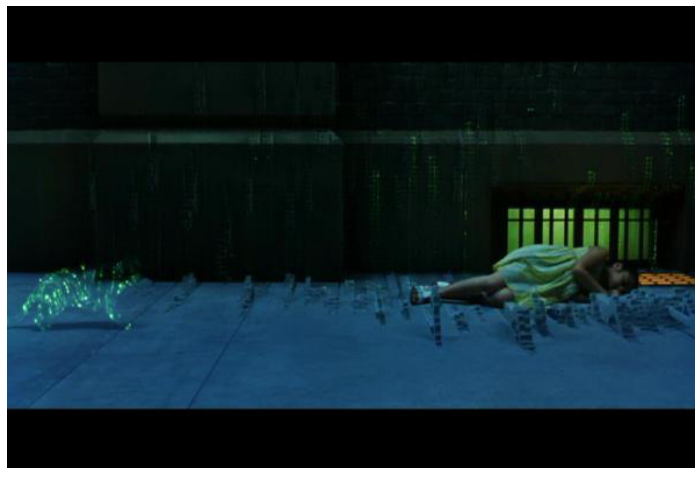

Fig. 18 - Cena de Matrix Revolutions

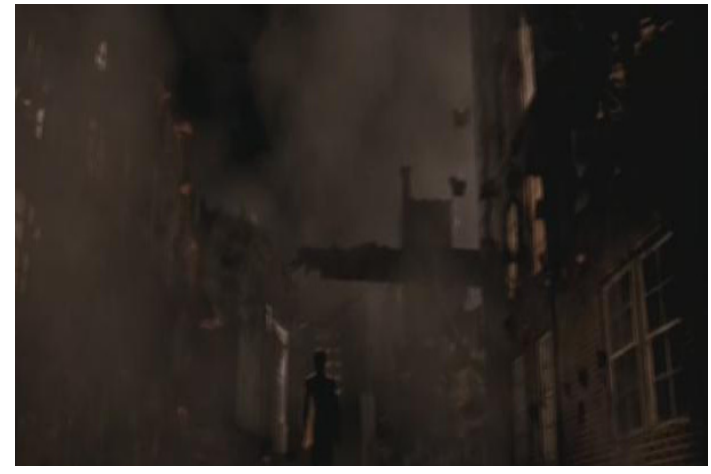

Fig. 19 - Cena de Cidade das Sombras

Apesar de Matrix ser virtual e Cidade das Sombras atual (real), os pedaços que voam e se recombinam são semelhantes, como um quebra cabeças que se monta automaticamente ou um sistema operacional de computador que faz seu "re-start".

Ao final de ambos, o sol nasce no horizonte da cidade (Figuras 20 e 21). Como um sinal de paz, de energia renovada nos espaços antes castigados pela guerra e pela dominação. O sol é um sinal de renovação do mito cosmogônico, como diz Mircea Eliade, "com efeito, a Noite da qual nasce o Sol todas as manhãs simboliza o Caos primordial, e o nascer do Sol é uma réplica da cosmogonia" (ELIADE, 2006, p. 77). 


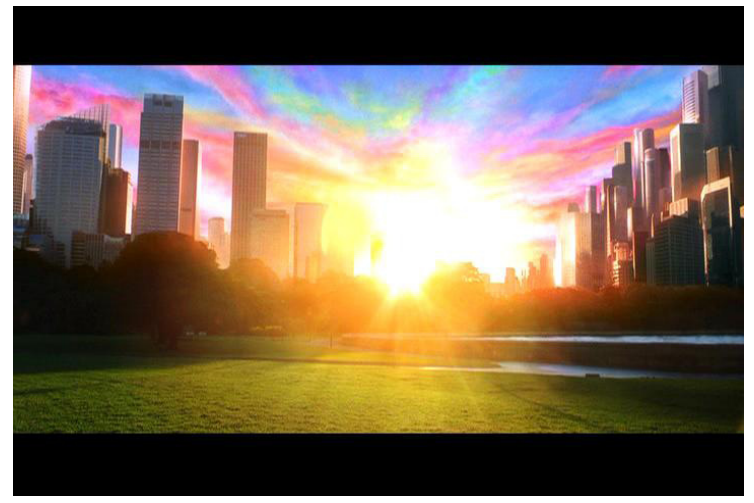

Fig. 20 - Cena final de Matrix Revolutions

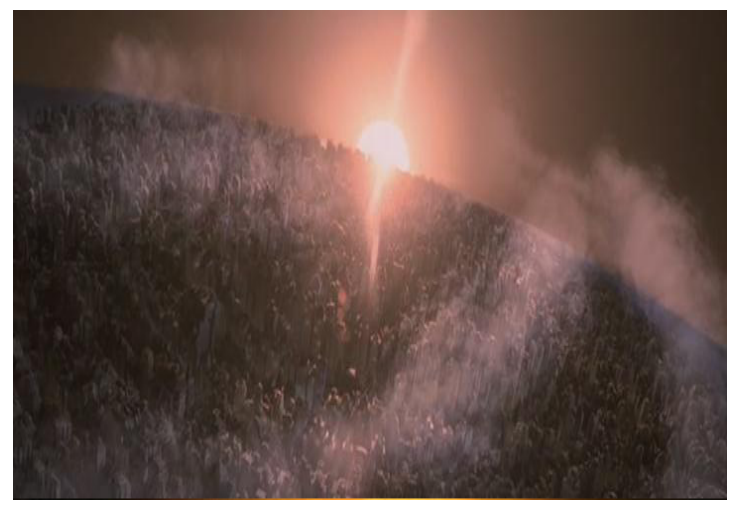

Fig. 21 - Cena final de Cidade das Sombras

Algo precisa ser destruído para dar lugar a algo novo, uma nova versão, um novo jogo, uma nova forma de "usar" o mundo. A autodestruição para um renascimento. Assim são as novas tecnologias do digital (e do material também). Elas precisam ser ultrapassadas para que uma nova versão seja lançada e a indústria possa vender mais, possa fazer girar a roda do capitalismo.

Outra influência bastante atuante em Matrix e outros filmes de ficção científica é o romance Neuromancer, de William Gibson. Esse romance cyberpunk de 1984 influenciou diversas outras obras, como o Fantasma do futuro (1995) e Johnny Mnemonic (1995), para citar apenas algumas.

Pelo poder do imaginário que a obra de Gibson deixou, existe a impressão de que Matrix copiou determinadas cenas desses outros filmes, quando na verdade elas foram "seduzidas" por Neuromancer.

A principal referência, repetida em diversos filmes, é a capacidade do cérebro se conectar diretamente com a máquina através de um orifício em sua nuca. O historiador James Gun discorre sobre Neuromancer acerca dessa característica:

Em Neuromancer, um dispositivo inserido cirurgicamente no cérebro de Case, o "caubói" da realidade virtual, permite-Ihe "lançar-se" no "ciberespaço", descrito por Gibson como a projeção de "uma consciência desincorporada numa ilusão consensual, que era a matriz". (Talvez essa tenha sido a primeira vez que se usou o termo "matriz" para representar um ambiente de realidade virtual) (Gunn, 2003, p. 76). 
Segue abaixo alguns exemplos que podem ter usado da influência de Neuromancer e sua ligação com o cérebro. Na figura 22, o conector usado em Matrix (1999), que leva Neo a se conectar com a Matrix e com os simuladores da nave Nabucodonosor, é sua porta de entrada para o ciberespaço. Na figura 23, Johnny Mnemonic (1995), um filme pouco conhecido, mas que tem forte influência do cyberpunk, tem o mesmo ator de Matrix - Keanu Reeves - como protagonista.

Esse filme se passa em 2021, quando o mundo inteiro está conectado através de uma gigantesca internet. Metade da população é afetada pela doença NAS, uma espécie de epidemia do século XXI, que consiste em ter uma alergia fatal às ondas eletromagnéticas. Um mensageiro cibernético (Keanu Reeves) é contratado para transportar 320 gigabytes que contêm a cura para este mal em um chip implantado no seu cérebro. Entretanto, seu cérebro está saturado e um grupo planeja impedi-lo de levar essa informação. Desse modo, ele tem apenas um dia para salvar a si e ao mundo.

A figura 24 é uma cena da animação futurista O fantasma do Futuro (1998), do diretor japonês Mamoru Oshii. Nesse filme, que se passa 2029, cyborgs tentam impedir o alastramento de crimes via redes e centros de informação.

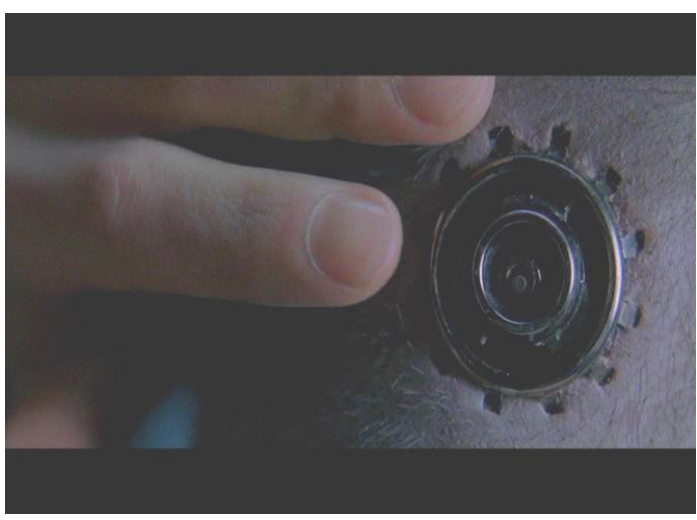

Fig. 22 - Cena do filme Matrix

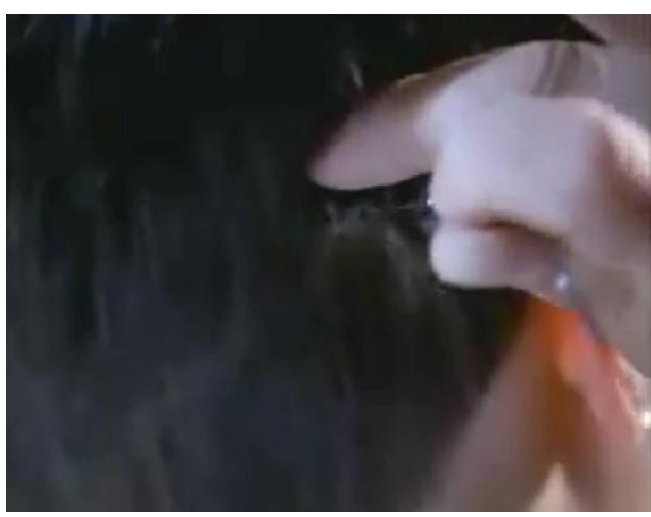

Fig. 23 - Cena do filme Johnny Mnemonic 


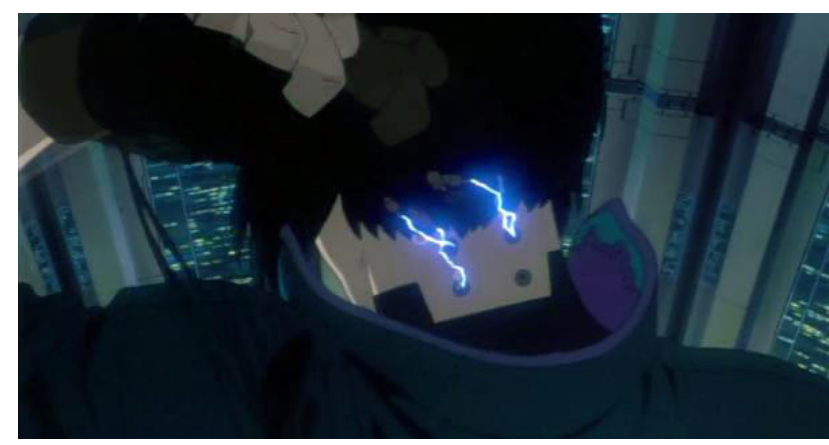

Fig. 24 - Cena do filme Fantasma do Futuro

Em todos esses exemplos, existe uma conexão direta com a máquina via cabos, mostrando que o homem é parte integrante da evolução tecnológica e dela faz parte.

Outro filme com algumas influências tecnológicas no cinema foi Westworld (1973), dirigido e escrito por Michael Crichton ${ }^{4}$. Neste filme vemos dois amigos que viajam para um parque temático, onde é possível ficar imerso em mundos construídos para satisfazer os clientes: Velho Oeste norte-americano, Idade média e Roma antiga. Tudo no parque é montado com alta tecnologia de robôs "quase" humanos que realizam os desejos de seus clientes ansiosos por diversão sem remorso. Estes robôs se rebelam causando a morte dos cientistas que os criaram e dos visitantes do parque.

A comparação desse filme com Matrix está na forma de imersão dos personagens em um mundo construído pela máquina e de como esse mundo passa a ser controlado por ela após uma rebelião da tecnologia. Além das igualdades de enredo, existe uma igualdade no uso da estética da máquina dos anos 70 que permanece em Matrix dos anos 90. Nas cenas abaixo temos uma referência aos números em terminais de fósforo verde. Os antigos terminais de mainframe ${ }^{5}$ da década de 60 e 70 tinham essa cor e diversos filmes se inspiram nesse imaginário tecnológico para referenciar a máquina. Abaixo seguem alguns exemplos: 


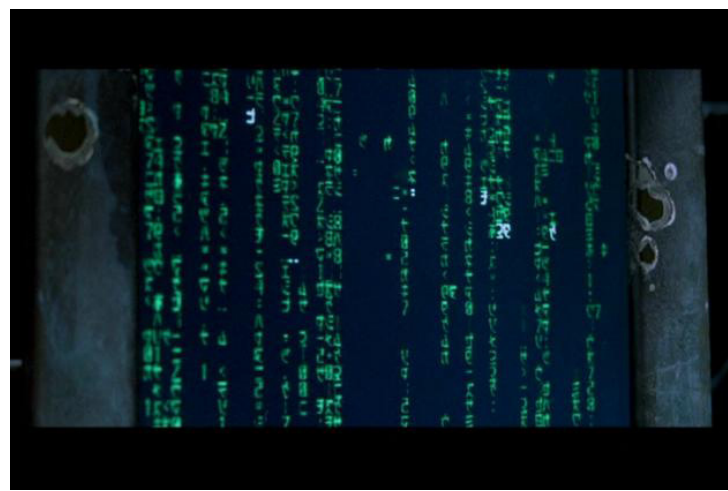

Fig. 25 - Cena de Matrix - Tela do operador

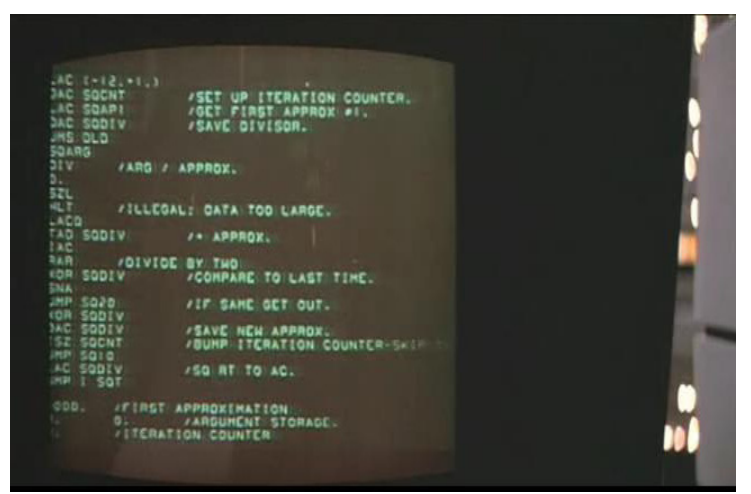

Fig. 26 - Cena de Westworld - Tela do operador

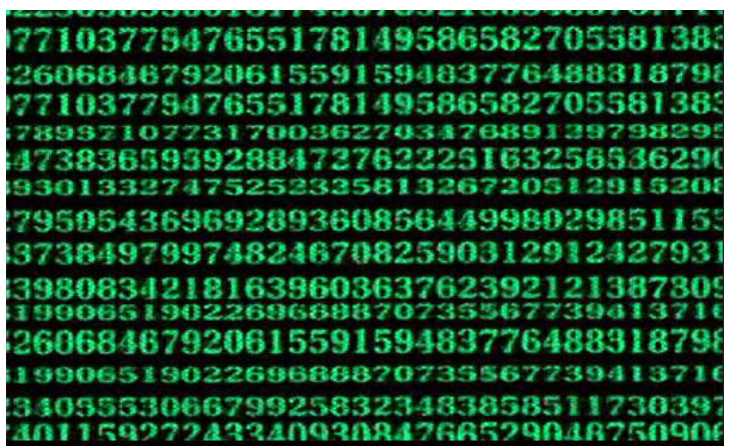

Fig. 27 - Cena de Fantasma do Futuro - Tela do início do filme

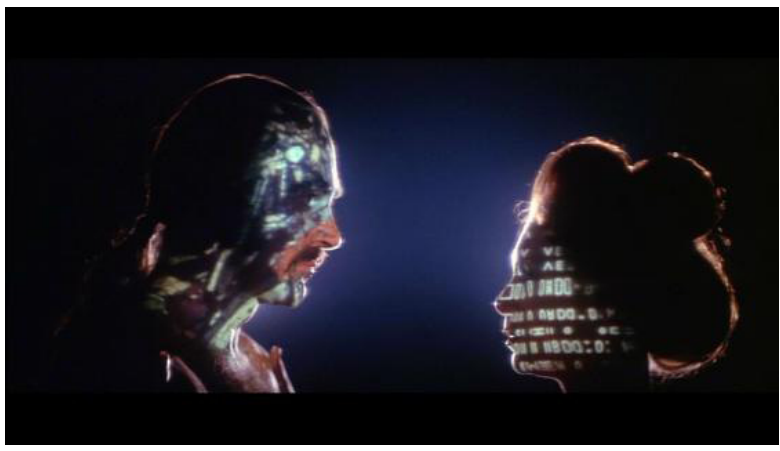

Fig. 28 - Cena de Zardoz - Números no rosto da garota 
Esses mesmos caracteres verdes são usados para os créditos iniciais de vários filmes:

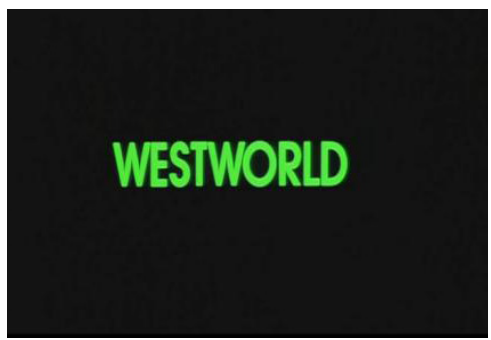

Fig. 29 - Título na abertura de Westworld

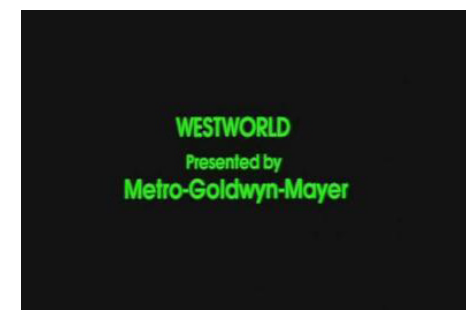

Fig. 32 - Créditos em Westworld

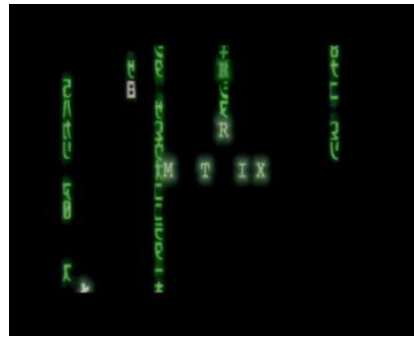

Fig. 30 - Título na abertura de Matrix

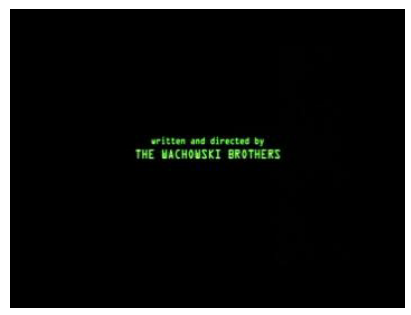

Fig. 33 - Créditos em Matrix

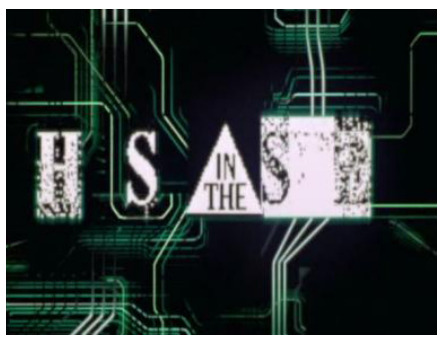

Fig. 31 - Título na abertura de Fantasma do Futuro

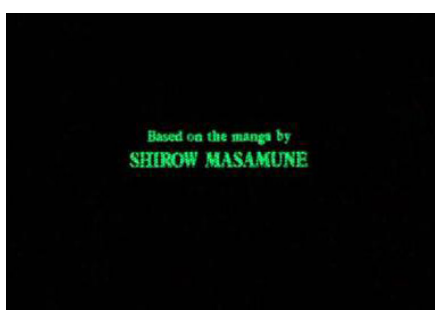

Fig. 34 - Créditos em Fantasma do Futuro

Uma pergunta: os terminais evoluíram se compararmos o operador em Matrix (1999) (figura 35) e o operador em Westworld (1973) (figura 36)?

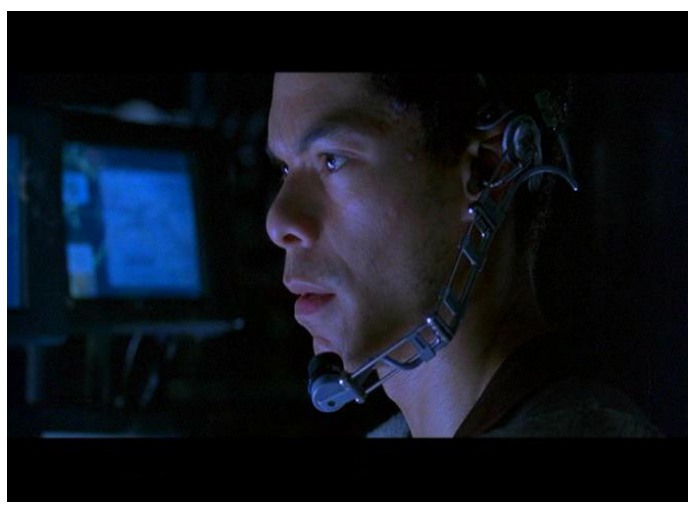

Fig. 35 - Cena de Matrix

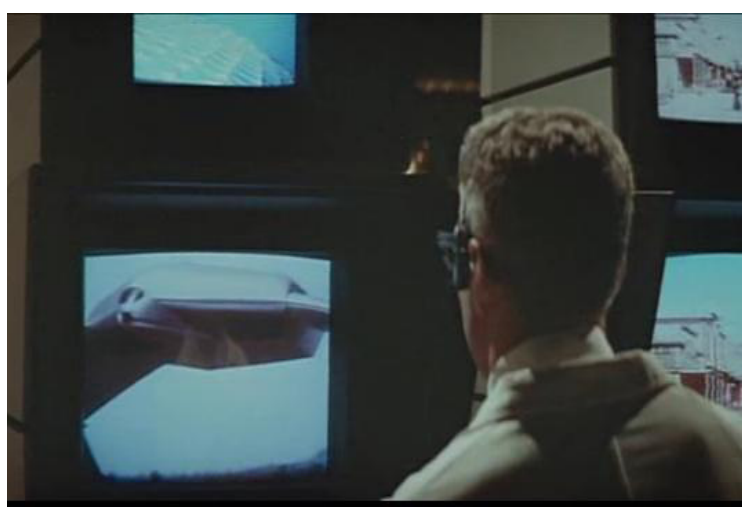

Fig. 36 - Cena de Westworld

Provavelmente os criadores de Matrix foram influenciados por esse imaginário dos filmes da década de 70, inclusive na representação da tecnologia e até mesmo na técnica de compor algumas cenas. 
Outro espaço que também se repete nos filmes analisados são os das cidades mostradas de um ângulo panorâmico, como se uma aeronave sobrevoasse a cidade e a mostrasse desse ângulo. As cidades são núcleos importantes onde a vida urbana tem sua trajetória, seja ela real ou virtual. Seria normal, em filmes que tratam de tecnologia, que o computador fosse mostrado em sua virtualidade, talvez até imaterial ou fora das normas e padrões da sociedade. Mas o que ocorre é uma afirmação dos espaços físicos, de nossa morada e da metrópole triunfante, que irradia sua grandiosidade.

Os núcleos urbanos são uma das expressões da tecnologia e engenhosidade humana, e talvez esse imaginário das cidades vistas do alto reforce a necessidade de defendermos nosso lugar de morada. A cidade é isso, um aglomerado de casas, de lugares para a morada do corpo, que os filmes sobre a virtualidade acabam por representar. Como diz Bachelard:

$\mathrm{Na}$ vida do homem, a casa afasta contingências, multiplica seus conselhos de continuidade. Sem ela, o homem seria um ser disperso. Ela mantém o homem através das tempestades do céu e das tempestades da vida. É corpo e é alma. É o primeiro mundo do ser humano (Bachelard, 1993, p. 26).

Abaixo, cenas de Matrix (Figura 37), Tron (Figura 38), Fantasma do Futuro (Figura 39) e Cidade das Sombras (Figura 40) em que existem representações espaciais das cidades, tanto para a morada do corpo, como em Cidade das Sombras e Fantasma do Futuro, como para a morada da mente como em Matrix e Tron. 


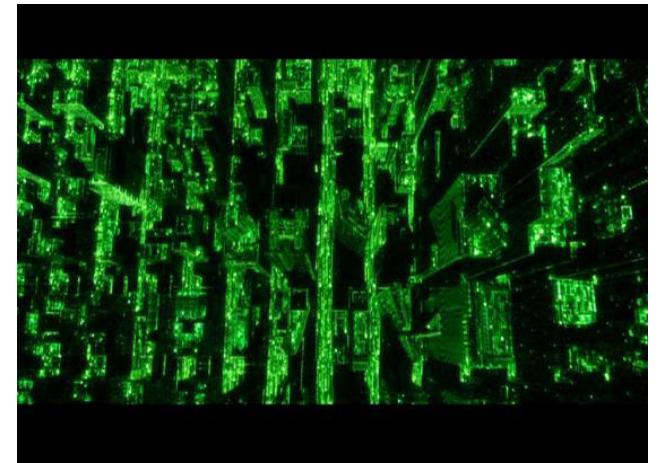

Fig. 37 - Cena de Matrix Revolutions

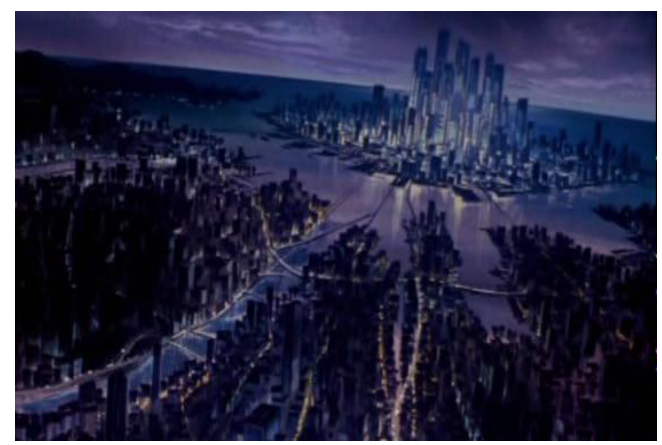

Fig. 39 - Cena de Fantasma do Futuro

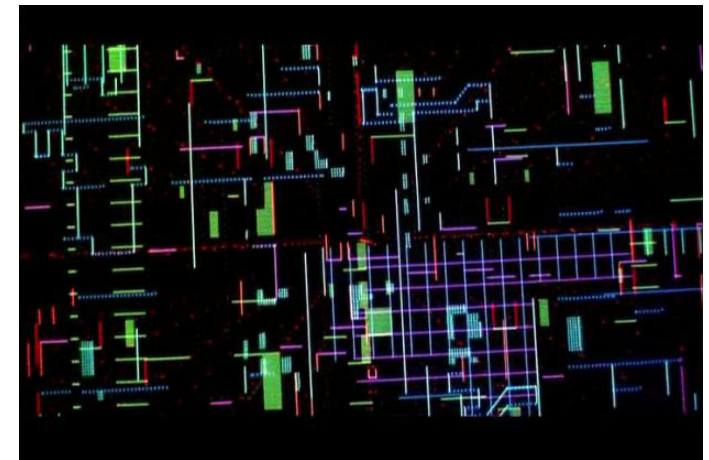

Fig. 38 - Cena de Tron

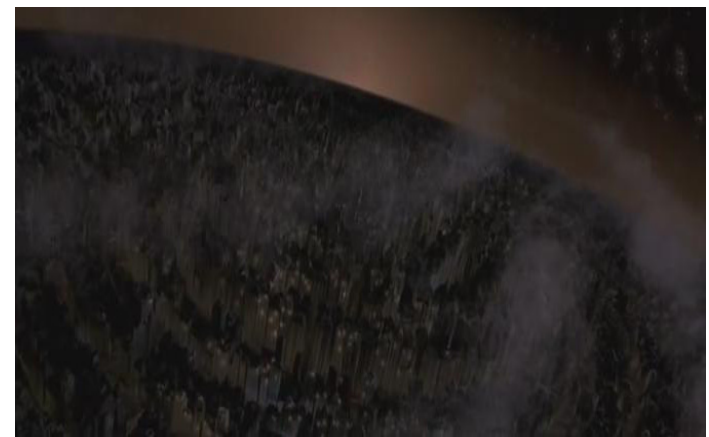

Fig. 40 - Cena de Cidade das Sombras

Como curiosidade, seguem outros momentos em que existem referências entre os filmes, como os soldados em Matrix e Fantasma do Futuro, vistos abaixo (Figuras 41 e 42):

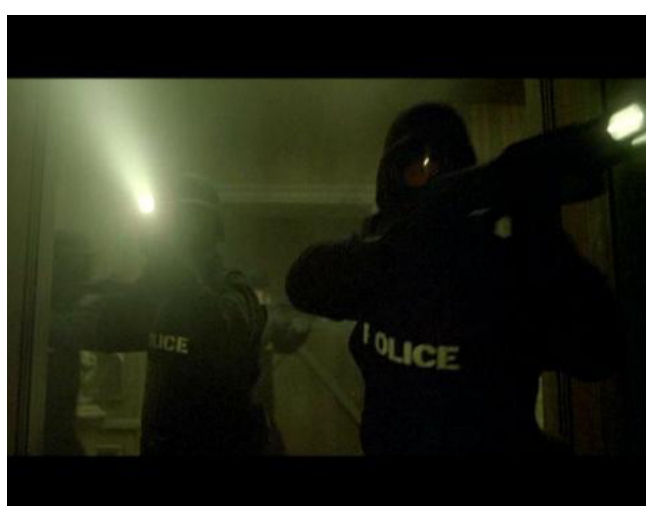

Figura 41 - Cena de Matrix

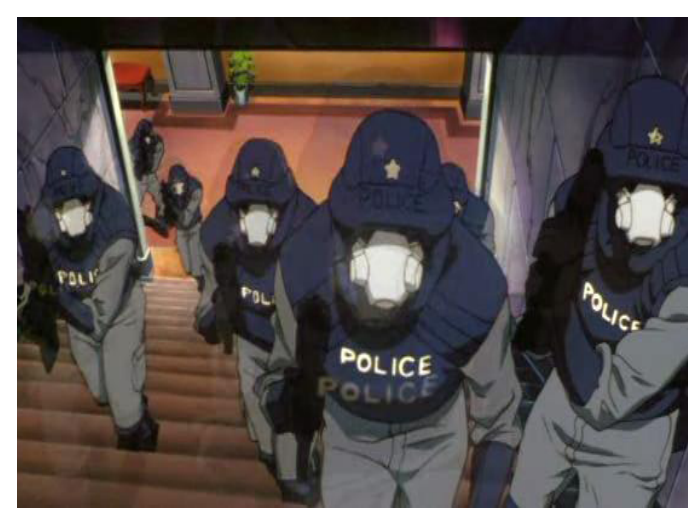

Figura 42 - Cenas de Fantasma do Futuro

Todos esses filmes alimentaram de alguma forma um imaginário latente que, depois de ativado, se consolidou e permeou Matrix de diversas formas. São reflexos de uma sociedade que usa a tecnologia de forma acelerada e cada vez 
mais integrada ao universo digital e virtual. Ao mesmo tempo, essa sociedade teme seus efeitos em médio prazo, pois a maioria dos filmes fala de um futuro não muito distante do que vivemos e dos problemas que teremos caso nossas criações se tornem inteligentes o suficiente para ter o controle de nossas vidas.

O cinema continua sendo a melhor forma de contar histórias e exorcizar os fantasmas que nos assustam a cada nova descoberta tecnológica, seja em forma de chip eletrônico, retratada em Zardoz e Tron, ou como o ciberespaço imersivo e complexo de Matrix. 


\section{Referências}

BACHELARD, G. A Poética do espaço. São Paulo: Martins Fontes, 1993.

ELIADE, M. Mito e realidade. São Paulo: Perspectiva, 2006.

FELINTO, E. A religião das máquinas: ensaios sobre o imaginário das ciberculturas. Porto Alegre: Sulina, 2005.

GUNN, J. "O paradoxo da realidade em Matrix". In: YEFFETH, G. (Org.). A Pílula Vermelha. São Paulo: Publifolha, 2003.

\section{Filmografia}

BOORMAN, J. Zardoz. Inglaterra, John Boorman Productions, 1974, 106 min.

CHUNG, P.; JONES, A.; KAWAJIRI, Y.; KOIKE, T.; MAEDA, M.; MORIMOTO,K.;

WATANABE, S. Animatrix. EUA, Warner Bros, 2003, 102 min.

CRICHTON, M. Westworld - Onde ninguém tem alma. EUA, Metro-Goldwyn-Mayer, 1973,88 min.

CRONENBERG, D. eXistenZ. Canadá/Inglaterra, Alliance Atlantis Communications, 1999, $97 \mathrm{~min}$.

. Videodrome - a síndrome do vídeo. Canadá, Universal Pictures,

$1983,87 \mathrm{~min}$

HEFFRON, R.T. Future World. EUA, American International Pictures (AIP), 1976, 104 $\min$.

LISBERGER, S. Tron - Uma Odisséia Eletrônica. EUA, Walt Disney, 1982, 96 min.

LONGO, R. Johnny Mnemonic, o Cyborg do Futuro. EUA, TriStar Pictures, 1995, 98 min.

ORECK, J. Matrix Revisited. EUA, Warner Bros, 2001, 123 min.

OSHII, M. O fantasma do futuro. Japão/Inglaterra, Bandai Visual Company, 1995, 82 $\min$.

PROYAS, A. Cidade das Sombras. EUA, New Line Cinema, 1998, 101 min. 
WACHOWSKI, B. Matrix. EUA, Warner Bros, 1999, 136 min.

Matrix Reloaded. EUA, Warner Bros, 2003, 138 min.

Matrix Revolutions. EUA, Warner Bros, 2003, 129 min.

1 Este artigo é baseado em análises apresentadas na dissertação de mestrado intitulada "Mundo paralelo virtual no cinema: um estudo do espaço em 'Matrix'".

2 Geraldo de Lima é mestre em Comunicação Contemporânea pela Universidade Anhembi Morumbi e especialista em criação visual e multimídia pela Universidade São Judas Tadeu. Participa atualmente do grupo de pesquisa da UAM sobre o tema "O Sagrado e o Cinema".

3 A obra é composta dos seguintes filmes: Matrix (1999), Matrix Reloaded (2003), Matrix Revolutions (2003), Animatrix (2003) e o documentário Matrix Revisited (2001).

4 Michael Crichton foi também o roteirista do filme Parque dos dinossauros, que fez grande sucesso sob a direção de Steven Spielberg e que mostra a evolução da tecnologia biológica que recria os dinossauros em laboratório. Michael Crichton estava escrevendo em 2008 um "remake" de Westworld, mas acabou falecendo antes de terminar a obra.

5 Mainframe é o termo usado para computadores IBM de "grande porte" criados na década de 70 e usados por grandes empresas até hoje em dia. 